\title{
Orifice of the Eustachian Tube
}

National Cancer Institute

\section{Source}

National Cancer Institute. Orifice of the Eustachian Tube. NCI Thesaurus. Code C33225.

The opening of the eustachian tube at its pharyngeal end. 